\title{
Polymerization stress evolution of a bulk-fill flowable composite under different compliances
}

Yongwen Guo ${ }^{\mathrm{a}, \mathrm{b}}$, Forrest A. Landis ${ }^{\mathrm{c}}$, Zhengzhi Wang ${ }^{\mathrm{b}}$, Ding Bai ${ }^{\mathrm{a}, \mathrm{b}}$, Li Jiang ${ }^{\mathrm{a}, \mathrm{b}}$, Martin Y.M.

$$
\text { Chiang, }{ }^{\mathrm{b}, *}
$$

${ }^{a}$ State Key Laboratory of Oral Diseases, Department of Orthodontics, West China School of Stomatology, Sichuan University, Chengdu 610041, China

${ }^{\mathrm{b}}$ Biosystems and Biomaterials Division, National Institute of Standards and Technology, Gaithersburg, MD 20899, USA

${ }^{c}$ Department of Chemistry, Penn State University - York Campus, York, PA 17403

${ }^{*}$ Corresponding author:

Martin Y.M. Chiang

Biosystems and Biomaterials Division, National Institute of Standards and Technology, Gaithersburg, MD 20899, USA; Tel.: +1-301-975-5186; E-mail: martin.chiang@nist.gov.

Official contribution of the National Institute of Standards and Technology; not subject to copyright in the United States. 


\section{Introduction}

Extensive efforts have been employed over the years to improve the physical and mechanical properties of photopolymerized dental composites that are used to restore the appearance and function of teeth[1]. As monomers used in dental composite resins react to form covalent bonds during the polymerization process, the volume of the resulting polymer contracts. Subsequently, enormous polymerization stresses (PS) can develop due to external constrains (i.e., tooth walls or substrates) during the process $[2,3]$. This stress is considered undesirable and could lead to deleterious clinical signs and symptoms, such as post-operative sensitivity, debonding, marginal discoloration, secondary caries, and cusp fractures[4-6]. Incorporating a larger amount of filler, increasing the molar mass or polarity of monomers, and tuning the reaction kinetics are some of the strategies used to mitigate the adverse effects of polymerization shrinkage. Conventionally, the restorative resins are incorporated with a high content (ca. $80 \%$ by mass) of silica filler. The presence of filler in these composite resins, known as "packable composites", reduces the overall shrinkage relative to an unfilled resin. In addition, these composites have an increased modulus due to the presence of the filler which improves the hardness and performance life time of the composite in the tooth cavity. However, PS is primarily determined by the reciprocal relationship between the shrinkage and modulus. Recently, with modifications in the filler content and/or the organic matrix, a new generation of composites known as "bulk-fill flowable composites" has been introduced which claim to exhibit low PS as one of the main advancements[7, 8]. The lower filler content of the bulk-fill flowable composites (ca. 60 mass \%) results in a lower modulus and is considered to be the main contributing factor to the reduced PS $[9,10]$. It has been recommended that most of the bulk-fill flowable materials be used as base materials in dental cavities, which are then veneered with 2 
$\mathrm{mm}$ of the higher filler content packable composites with relatively better mechanical properties such as hardness, stiffness and strength $[8,10]$. Besides showing the reciprocal relationship between the shrinkage and modulus, many studies also indicate that the effect of the filler content on PS can be significantly influenced by the compliance of the testing systems used to measure the PS[11, 12]. Clinically, the compliance is characterized by the geometry of the prepared tooth cavity and the stiffness (or compliance) of the remaining tooth structure $[13,14]$. Thus, it remains elusive whether bulk-fill flowable materials always generate relatively lower PS under varied compliances, or whether the flowable composites are suitable as a base material in the dental restoration. The main goal of this study is to compare the evolution in the PS of a bulk-fill flowable composite under different compliances to a conventional packable composite during polymerization.

Numerous studies have investigated the effect of filler content on PS with different testing systems with conflicting results. This could be attributed to the fact that these studies did not take into account the compliance of the testing system as a systematic variable. Condon et al. evaluated the magnitude of the PS of a variety of commercial composites containing different levels of filler content using a mechanical testing instrument with very low compliance and concluded that the PS increased with increasing filler content[15]. Boaro et al. reported the same trend of PS in relation to filler content by investigating seventeen commercial dental composites using a stress-strain analyzer with a feedback system, which allows for a near zero compliance [16]. Braga et al. found an inverse trend when evaluating the PS of eight, and then twenty in their later study, experimental composites loaded with incremental filler content in a universal test machine using an acrylic as a bonding substrate. The presence of the acrylic material resulted in an increase in the compliance of the testing system $[17,18]$ relative to the previously mentioned 
studies where glass was usually adopted as the bonding substrate. Stansbury et al. measured the PS of five composites with incremental filler content using an instrument with relatively low compliance[19]. They reported no significant statistical difference in the PS due to the filler content. Nevertheless, these studies of PS development as function of filler content were performed under testing systems with a fixed compliance that might not be clinically relevant; no systematic variation of compliance has been incorporated in their studies. Recently, Fok et al. developed a mathematical model to predict the development of PS and reported that differences in the compliance of the experimental systems would significantly influence the effect of the filler content on the PS. This study showed that with increasing filler content, the PS could increase or stay constant depending on the compliance of the testing system[12]. Recently, a work conducted in our lab using experimental and analytical approaches to systematically study the effect of filler content on PS using model composites with incremental filler contents $(0 \%$ to $75 \%$ by mass). This study demonstrated that the PS actually increases, decreases, or remains constant with increasing filler content depending upon the instrumental compliance [20]. This work also emphasized the importance of the testing systems compliance in obtaining unbiased or misleading test results in PS evaluation.

Another important aspect of the polymerization of dental materials is the degree of conversion (DC) of the methacrylate monomers to polymer. This conversion is correlated with the volumetric shrinkage and modulus development in the polymerization process. It has been shown that the degree of conversion of the methacrylate monomer progressively decreases with increasing filler content $[19,21]$; an inverse relationship was also found between the filler content and the magnitude of the polymerization exotherm (i.e., less filled flowable composites would show higher DC and exotherm than conventional composites[22-24]). The exotherm 
would affect not only the pulp vitality during dental treatment, but also the polymerization process[25]. Therefore, measurements of DC and exotherm are indispensable for better interpretation of the PS evolution during polymerization process.

In the present study, real-time and simultaneous measurements of the PS, DC and exotherm were performed on commercially available bulk-fill flowable and packable composites using a NIST-developed cantilever-beam based instrument [26, 27]. The key advantage for the simultaneous measurements is that these properties can be correlated directly, thus providing higher measurement confidence and a more in-depth understanding of the network formation process. Unlike other stress measurement instruments with a fixed compliance (high or low), the instrument used in this study readily allows for a variety of compliances to be employed. A systematic variation of instrument compliance comparable to possible clinical compliances of tooth cavities was obtained by changing the sample position along the cantilever beam. The instrument was coupled to a fast near infrared (NIR) spectrometer collecting spectra in transmission mode to measure the DC during the polymerization process. The polymerization exotherm was determined with a microprobe thermocouple embedded into the center of the sample. Our results indicated that, depending on the compliance of testing system, the PS generated from the bulk fill flowable composite is not always lower than that from the higher filler content packable composite as is usually expected. Nevertheless, the bulk-fill flowable composite develops less PS than packable composite under the lower compliances studied. This validates the use of bulk-fill flowable composite as a base material in clinical procedures. The bulk-fill flowable composite shows a higher exotherm and DC than the packable composites but neither the exotherm nor DC are dependent on the compliance of the instrument. It is expected 
that the significantly higher exotherm induces a greater thermal expansion of the bulk-fill flowable material which contributes to the reduced final PS under low compliances.

\section{Materials and Methods ${ }^{\star}$}

Two composite materials from 3M ESPE (St. Paul, MN, USA) were investigated(Table 1). One composite was the bulk fill flowable composite, Filtek Bulk Fill(FBF). This FBF composite has a reduced filler content which lowers its viscosity and allows free flow into the cavity. It is meant to be used in a single application to completely fill the cavity followed by photo curing; however a veneer cap of a higher modulus composite is often required. The second composite was the traditional universal methacrylate-based composite, Filtek Z250 (Z250) with a higher filler content and consequently a higher viscosity. It is typically used in a conventional filling application where $2 \mathrm{~mm}$ incremental layers of the material are applied and cured to fill the entire cavity. All experiments were conducted under a yellow light environment to minimize premature photopolymerization at an initial temperature of $22 \pm 1{ }^{\circ} \mathrm{C}$.

In this study, a NIST-developed cantilever-beam based instrument (Fig. 1) was coupled to a high-speed data acquisition NIR spectrometer and a microprobe thermocouple to enable real-time simultaneous measurement of polymerization stress (PS), degree of conversion (DC), and exotherm during the polymerization[27]. The instrument was constructed according to design criteria following first principles of mechanics to provide the accuracy and sensitivity of the PS measurement[26]. The desired compliance of the testing instrument can be easily achieved by varying the sample position along the cantilever beam. In order to generate PS

\footnotetext{
- Certain commercial materials and equipment are identified in this manuscript in order to specify adequately the experimental and analysis procedures. In no case does such identification imply recommendation or endorsement by the National Institute of Standards and Technology (NIST) nor does it imply that they are necessarily the best available for the purpose.
} 
values that most closely reflect a clinical situation, a rigid steel beam (modulus: 203GPa; width: $6.32 \mathrm{~mm}$; height: $12.65 \mathrm{~mm}$ ) that provides compliances ranging from $0.3327 \mu \mathrm{m} / \mathrm{N}$ to 12.3215 $\mu \mathrm{m} / \mathrm{N}$ was selected. A capacitive displacement sensor with $20 \mathrm{~nm}$ resolution (Driver Model: CPL190, Probe Model: C18-13, Lion Precision, St. Paul, MN) was used to detect the beam deflection for calculating the PS development. The analog data detected by the sensor were collected using the LabView software program (National Instruments, Austin, TX) via a 24-bit DAQ device (USB-2404-10, Measurement Computing, Norton, MA).For both composites, at least three replicates were tested at each position on the beam. Detailed experimental procedures can be obtained from previous publications $[26,27]$. The size of the specimen disk was $2.5 \mathrm{~mm}$ in diameter and $2 \mathrm{~mm}$ in height. AQHL $75^{\mathrm{TM}}$ curing lamp (Dentsply-Caulk, Milford, DE) was used to provide the irradiance intensity of $500 \pm 10 \mathrm{~mW} / \mathrm{cm}^{2}$, measured with a Cure Rite radiometer (model \#8000, EFOS Inc, Williamsville, NY). The irradiation starting and ending times were controlled by the LabView program through a controllable power outlet, such that the data collection and the photoactivation were synchronized. Upon photopolymerization, the composite shrinkage induced a deflection in the cantilever beam, which was recorded by the displacement sensor at the free end of the beam. Using this displacement and the known beam compliance, the PS was then calculated usinga beam formula [27]. For all the samples, the DC was measured using the coupled NIR spectrometer by assessing the variation in the ratio of the absorbance intensities of the methacrylate functional group $\mathrm{C}=\mathrm{C}$ peak centered at $1638 \mathrm{~nm}$. The real-time DC was calculated for each sample by taking the peak area of the uncured sample prior to irradiation (Area $\mathrm{uncured}_{\text {) }}$ and at each time point during the polymerization after irradiation (Area $\mathrm{a}_{\text {cured }}$ ) using the following formula: $\mathrm{DC}=1-\mathrm{Area}_{\text {cured }} / \mathrm{Area}_{\text {uncured }}[28]$. The temperature change during polymerization was also monitored (Fig. 1b) using a $100 \mu \mathrm{m}$ microprobe thermometer 
(Type T Quick-response PFA-insulated thermocouple probe from Cole-Palmer Instrument Company, Vernon Hills, IL) inserted into the center of the sample. The PS, DC and temperature change (exotherm) were simultaneously recorded at an interval of $0.15 \mathrm{~s}$ for $10 \mathrm{~min}$ using the LabView software. A Student's t-test was performed to identify the difference between the two composites at a significance level of $\mathrm{p}<0.05$ using statistical software (SPSS 17, IBM Inc., USA).

\section{Results and discussion}

Figure 2 shows typical real-time DC profiles obtained at various compliances for the flowable FBF composite and the packable Z250 composite (Figures 2a \& 2b, respectively). The DC profiles and the rate (first derivative) of DC development (Figures 2c \& 2d) of both composites appear similar regardless of the change in the instrumental compliance. It should be first noted that the increase in the noise of the $\mathrm{Z} 250$ composite relative to the FBF stems from the increase in the scattering due to the higher filler content of the Z250 material. In addition, the final DC (after $100 \mathrm{~s}$ ) of the FBF flowable composite is statistically slightly higher than that of Z250 composite (Figure 3 ) at all compliances measured. This could be attributed to the FBF having low viscosity stemming from the reduction in the filler content, the increase of UDMA content, and the addition of the Procrylat resin (Table 1). Both UDMA and Procrylat are monomers characterized by high molar mass similar to BisGMA but with a significantly lower viscosity [29]. The effect of compliance on the conversion has been controversial, with many studies assuming that compliance has minimal or no effects on the conversion $[11,30]$, while some showed that samples under lower compliance produced higher DC. It has also been claimed that the external tensile constraint increases the free volume of the material during polymerization which facilitates the mobility of the radical and monomer and produces a higher 
degree of conversion[31]. In the present study, Figure 3 shows that for these two composite systems, the compliance had no significant effect on the final degree of conversion.

As the monomer converts into polymer in these photopolymerization reactions, heat is produced in the sample. Figure 4a shows the total observed exotherm profile of the FBF and Z250 composites measured simultaneously with the DC and PS. The temperature rise observed during photopolymerization is caused by both the exothermic reaction and the light energy absorbed during irradiation. To separate these two effects, a second, identical irradiation was applied on the post-cured sample[22, 32] which only increases in temperature due to the light radiation. The composite material exotherm (Figure $4 \mathrm{~b}$ ) was then obtained by subtracting the cured sample irradiation temperature increase from the total observed temperature. It can be seen in Figure $4 \mathrm{~b}$ that the FBF sample produced a polymerization exotherm $\left(8.82 \pm 0.44{ }^{\circ} \mathrm{C}\right)$ that was almost as twice that of $\mathrm{Z} 250\left(4.52 \pm 0.22{ }^{\circ} \mathrm{C}\right)$. The temperature profile shown in Figure $4 \mathrm{~b}$ is independent of the compliance of the testing system studied (data not shown). The higher temperature rise of FBF can be explained mainly by the lower filler content that allows more monomers to be incorporated in the composite and involved in the polymerization process, thus generating more heat[24, 33, 34]. Because of the higher concentration of monomer, lower filler content, and greater exotherm, the FBF composite should undergo higher thermal expansion than Z250.

Shown in Figure 5 is the PS evolution of the FBF and Z250 composites evaluated under various compliances of the cantilever-beam based instrument. Both sets of data show that little difference exists in the general trend of the development of PS; each composite displays the typical observation that the stress increases rapidly during the initial stages of the polymerization and levels off over time (Figures 5a \& 5b). Also shown in this figure is the effect of instrument 
compliance on the measured stress in both composites. In general, the composites show a lower final stress as the compliance of the instrument increases. When comparing the final stress after $100 \mathrm{~s}$ in both the FBF and Z250 samples, virtually no difference is observed at the highest instrument compliance of $12.3215 \mu \mathrm{m} / \mathrm{N}$. However, as the compliance of the instrument decreases, the highly filled Z250 composite shows a greater increase in the final stress than does the flowable FBF composite. Another striking difference between the PS profile of the Z250 and FBF composites occurs in the early stages of the photopolymerization process. This is more clearly shown by expanding these early stages of the PS profile (Figures $5 c \& 5 d$ ). The FBF composite shows an initial increase in stress followed by a sudden drop in the PS regardless of the compliance studied (Figure 5c). The maximum of the bump in the PS profile occurs at ca. $3.5 \mathrm{~s}$ after the curing lamp has been turned on. This decrease continues until ca.4.4s when the PS again begins to increase but at a slower rate as compared to the initial rapid rise near $1.5 \mathrm{~s}$. The temporary decrease in the PS is more prominent when the sample was tested under the low compliance constraints (Figure 5c). In comparison, the highly filled Z250 composite shows no evidence of a bump in the PS profile (Figure 5d). The drop in the stress during the development of PS in the FBF composite (Figures 5c) is associated with the thermal expansion of the composite during photopolymerization.

Figure 6 compares the previously discussed PS profile (Figure 6a) of the FBF composite with the thermal profile (Figure 6b) taken simultaneously. By comparing the time at which the temperature reaches the peak and the time at which the PS drops to the minimum, one can see that the two time points coincide. These results show that initially (at ca. $1.5 \mathrm{~s}$ ), polymerization shrinkage stress begins to develop in the sample, but eventually the combination of the polymerization exotherm and the radiant heating cause the sample to expand faster than the 
shrinkage increases. This causes the PS to go through a maximum near $3.5 \mathrm{~s}$ followed by a brief decrease in the PS. Once the exotherm of the reaction goes through its maximum at ca. $4.4 \mathrm{~s}$, the contraction of the sample arising from polymerization overtakes the thermal expansion, and the stress once again increases, although at a slower rate than the initial increase in the PS immediately observed after the curing lamp was turned on. This decrease in the stress is related to the coefficient of thermal expansion (CTE) and the exotherm of the photopolymerization. The UDMA and Procrylat used as substitutes for Bis-GMA in the FBF composite have similar molar mass and CTE as Bis-GMA. The major factor that affects the CTE of a composite is the filler content[33]. In addition, the greater relative density of methacrylate groups in the FBF composite also causes a greater overall exotherm in the polymerization relative to the more highly filled Z250 composite (Figure 4). Consequently, the stress drop observed in FBF arises from the combined effect of greater exotherm and CTE on the change in sample volume. For comparison, when a $4 \mathrm{~mm}$ diameter FBF composite was studied in the cantilever-beam instrument, similar peaks in the PS and exotherm were observed at the exact same spot as the profiles shown of Figure 6. No drop in the PS of the Z250 sample was ever observed since the increase in the stress from the sample contraction was able to outpace the smaller thermal expansion due to a lower exotherm. Watts et al. found that the thermal expansion due to elevated temperature in less filled composites is greater than the subsequent thermal shrinkage as the heat dissipates in the later stages of the polymerization process[22]. Thus, the less filled composite vitrifies with a total volume greater than that only arising from the polymerization shrinkage, resulting in a lower overall PS [35]. This is in agreement with a recent study which found that the exotherm contributes to a delay in vitrification and also imparts a thermal strain to the materials [19]. It is also consistent with the behavior observed by Watts et al. [25] and Yamasaki et al. [36], who 
concluded that a higher temperature leads to expansion of the resin composites and increases the free volume which could compensate for the increase in the stress.

A secondary goal of this study was to address the contradictory reports of polymerization stress arising from the various compliances of the common testing instruments. Figure 7 gives the final PS measured under different compliances at 10 min after irradiation for the FBF and Z250 composites. It can be seen the final PS decreased with an increase in the compliance of the cantilever-beam instrument for both composites. However, the FBF shows a significantly lower final PS than the Z250 composite when the compliance was less than approximately $4 \mu \mathrm{m} / \mathrm{N}$. At instrumental compliances greater than $4 \mu \mathrm{m} / \mathrm{N}$, the difference in the final PS between the FBF and Z250 composites becomes statistically negligible. One can argue that lower PS of the bulkfill flowable composites is mainly due to the lower filler content and resulting lower modulus, and that the lower viscosity releases the stress in the early stages of polymerization[9, 10]. Our results suggest that the thermal expansion that develops early produces a lower net shrinkage of the composite and results in a reduced rate of stress development relative to the initial PS rate development of the FBF composite; therefore thermal expansion is an important factor for reducing the overall PS while the lower modulus or viscosity of the composite play a lesser role. The effect of thermal expansion on the development of PS is less pronounced when the compliance of testing system becomes greater. This could be attributed to, at least in part, the effect of filler content on the PS [15, 17-19, 37]. The PS results of the present study confirm the mathematical model of Fok et al., which indicated that the effect of filler content on PS relies on the compliance of the constraint: less filled composites could produce similar PS as highly filled ones under certain ranges of high compliance [12]. Boaro et al. found a strong linear relationship between filler content and PS under low compliance systems, but this relationship was much 
weaker when the compliance was high [37]. Watts et al. also found that at high compliance, composites with high filler content, which could induce lower shrinkage, produce lower PS regardless of the higher Young's modulus[38]. Our recent systematic study[20] through experiments and a simple mathematical model indicate that at the high compliance configuration of the cantilever-beam based instrument, the PS decreased with increasing filler content over the entire filler content range studied. This is in line with the results shown in the inset of Figure 7 , in which the Z250 composite reveals a lower PS than that of the FBF composite at compliances of more than $8.0 \mu \mathrm{m} / \mathrm{N}$ although the $\mathrm{Z} 250$ has a higher filler content than the FBF composite.

In a recent paper, Lee et al. used an in-house instrument with zero compliance to measure the polymerization stress of a series of dental composites including FBF and Z250 [39]. In addition, an acoustic emission device was used in an effort to quantify the interfacial debonding that could occur during photopolymerization of the dental composites. It was reported that after 10 min, both the FBF and Z250 composites produced nearly identical PS and average acoustic emission events suggesting a similar photopolymerization profile and a similar debonding response. In comparison, our studies suggest that these PS results are valid only at high instrument compliances (Figure 7). In addition to the FBF and Z250 composites resins, Lee, et al. examined a Filtek Z350 XT flowable composite (Z350 from 3M ESPE, St. Paul, MN, USA) which has a similar low filler content (65 mass\%) as the FBF composite, yet uses dimethacrylate monomers similar to that of the F250 composite. The Z350 composite has a low viscosity and handles much like the FBF composite; however it is expected to be used as a conventional composite (i.e., incremental layering) when filling dental cavities. Lee et al. reported that the Z350 composite developed nearly a 50\% increase in the PS relative to the FBF and Z250 composites and also produced a larger number of acoustic events during the photopolymerization 
suggesting a greater degree of debonding due to the greater polymerization shrinkage stress [39]. When studied using the NIST cantilever-beam instrument, the PS profile of the Z350 composite was nearly identical to the profile of the highly-filled Z250 composite (Figure 7); no dramatic increase in the PS was observed for the Z350 sample even using similar sample dimensions. However, at lower instrument compliance, both the Z250 and Z350 composites produced a greater polymerization stress than the flowable FBF composite. This study has shown that for dental restorative resins, a complex relationship exists between the filler content, the type/ratio of dimethacrylate monomers, and the compliance of the instrument when determining the final stress in the sample. A systematic study to take the advantages of the cantilever-beam instrument[26] should be underway to understand how mechanistically and kinetically these factors affect the performance of dental restorative composites.

Clinically, the compliance of a prepared tooth cavity varies and thus the PS depends on the remaining tooth structure and its geometry[14]. It has been reported that the cusp compliance of a mesial-occlusal-distal (MOD) cavity of $1.5 \mathrm{~mm} \times 2 \mathrm{~mm}$ or $3 \mathrm{~mm} \times 2 \mathrm{~mm}$ in a premolar was $2.96 \pm 0.20 \mu \mathrm{m} / \mathrm{N}$ and $3.32 \pm 0.41 \mu \mathrm{m} / \mathrm{N}$, respectively. The wider bucco-lingual cavity showed more compliance while the molar may have less compliance than the premolar because of the thicker cavity walls $[13,14]$. Considering that the bucco-lingual width of a premolar is smaller than that of a molar, the premolar may be more compliant than the molar because of its thinner cavity walls. Thus, in many clinical situations, such as molar tooth restorations, tooth compliance may be less than that measured in the study above. Additionally, the inner part of the cavity wall may have lower compliance, because the above value was obtained from measurements near the cusp tip. Recently, Rodrigues et al. analytically calculated the compliance for Class I model cavities with a finite element method and found that the mean compliance located at the corner 
region was $0.403 \mu \mathrm{m} / \mathrm{N}$ ranging from 0.204 to $0.863 \mu \mathrm{m} / \mathrm{N}[40]$. Therefore, when bulk-fill flowable composites are clinically used as the base at the inner and the corner part of a cavity, where the compliance is low, the polymerization shrinkage stress of the FBF would be significantly lower than that of Z250 according to results of the present study.

\section{Conclusions}

While the bulk-fill flowable composites are expected and have been reported to generate lower polymerization shrinkage stress (PS) than the conventional packable composites, our results show that the PS is dependent upon the compliance of the testing instrument. High compliance of the constraint eliminates the difference in the PS between the bulk-fill flowable and packable composites. Nevertheless, the bulk-fill flowable composite develops less PS than the packable composite under lower compliances. The greater exotherm of the bulk-fill flowable composite measured during polymerization induces significant thermal expansion, which acts as one of the dominant contributing factors to the mechanism of reduced final PS under low compliances. Our results also validate the use of the bulk-fill flowable composite as a base material at the inner or corner part of a prepared cavity, where the compliance is low, as the composite will result in a reduced final PS. In this study, only one single brand of composite was tested and a direct extrapolation of the results observed in the present study to all other composites may not be valid since the composition and chemistries are different. However, the general trends observed are expected to be applicable to other bulk-fill flowable composites.

\section{Acknowledgement}


This study is based on research that was funded throughthe China Scholarship Council and an

Interagency Agreement between the National Institute of Dental and Craniofacial Research and the National Institute of Standards and Technology, NIH/NIDCR [Y1-DE-7005-01].

\section{References}

[1] Cramer NB, Stansbury JW, Bowman CN. Recent advances and developments in composite dental restorative materials.J Dent Res 2011;90:402-16.

[2] Ferracane JL. Developing a more complete understanding of stresses produced in dental composites during polymerization. Dent Mater 2005;21:36-42.

[3] Marchesi G, Breschi L, Antoniolli F, Di Lenarda R, Ferracane J, Cadenaro M. Contraction stress of low-shrinkage composite materials assessed with different testing systems. Dent Mater 2010;26:947-53.

[4] Tantbirojn D, Versluis A, Pintado MR, DeLong R, Douglas WH. Tooth deformation patterns in molars after composite restoration. Dent Mater 2004;20:535-42.

[5] Calheiros FC, Sadek FT, Braga RR, Cardoso PE. Polymerization contraction stress of lowshrinkage composites and its correlation with microleakage in class V restorations. J Dent 2004;32:407-12.

[6] Tantbirojn D, Pfeifer CS, Braga RR, Versluis A. Do low-shrink composites reduce polymerization shrinkage effects? J Dent Res 2011;90:596-601.

[7] Campodonico CE, Tantbirojn D, Olin PS, Versluis A. Cuspal deflection and depth of cure in resin-based composite restorations filled by using bulk, incremental and transtoothillumination techniques. J Am Dent Assoc 2011;142:1176-82.

[8] Czasch P, Ilie N. In vitro comparison of mechanical properties and degree of cure of bulk fill composites. Clin Oral Investig 2013;17:227-35.

[9] El-Damanhoury H, Platt J. Polymerization Shrinkage Stress Kinetics and Related Properties of Bulk-fill Resin Composites. Oper Dent 2013.

[10]Leprince JG, Palin WM, Vanacker J, Sabbagh J, Devaux J, Leloup G. Physico-mechanical characteristics of commercially available bulk-fill composites. J Dent 2014;42:993-1000. 
[11]Min SH, Ferracane J, Lee IB. Effect of shrinkage strain, modulus, and instrument compliance on polymerization shrinkage stress of light-cured composites during the initial curing stage. Dent Mater 2010;26:1024-33.

[12]Fok AS. Shrinkage stress development in dental composites--an analytical treatment. Dent Mater 2013;29:1108-15.

[13]Lee IB, Cho BH, Son HH, Um CM, Lim BS. The effect of consistency, specimen geometry and adhesion on the axial polymerization shrinkage measurement of light cured composites. Dent Mater 2006;22:1071-9.

[14]Lee SH, Chang J, Ferracane J, Lee IB. Influence of instrument compliance and specimen thickness on the polymerization shrinkage stress measurement of light-cured composites. Dent Mater 2007;23:1093-100.

[15] Condon JR, Ferracane JL. Assessing the effect of composite formulation on polymerization stress. J Am Dent Assoc 2000;131:497-503.

[16]Kleverlaan CJ, Feilzer AJ. Polymerization shrinkage and contraction stress of dental resin composites. Dent Mater 2005;21:1150-7.

[17] Goncalves F, Kawano Y, Braga RR. Contraction stress related to composite inorganic content. Dent Mater 2010;26:704-9.

[18] Goncalves F, Azevedo CL, Ferracane JL, Braga RR. BisGMA/TEGDMA ratio and filler content effects on shrinkage stress. Dent Mater 2011;27:520-6.

[19] Shah PK, Stansbury JW. Role of filler and functional group conversion in the evolution of properties in polymeric dental restoratives. Dent Mater 2014;30:586-93.

[20]Wang Z, Chiang MYM. Effect of Filler Content on Polymerization Shrinkage Stress of Dental Composite Depends upon Cavity Compliance,submitted for publication, Dent Mater [21] Amirouche-Korichi A, Mouzali M, Watts DC. Effects of monomer ratios and highly radiopaque fillers on degree of conversion and shrinkage-strain of dental resin composites. Dent Mater 2009;25:1411-8.

[22]Alnazzawi A, Watts DC. Simultaneous determination of polymerization shrinkage, exotherm and thermal expansion coefficient for dental resin-composites. Dent Mater 2012;28:1240-9.

[23]Park JK, Hur B, Ko CC, Garcia-Godoy F, Kim HI, Kwon YH. Effect of light-curing units on the thermal expansion of resin nanocomposites. Am J Dent 2010;23:331-4. 
[24]Chang HS, Cho KJ, Park SJ, Lee BN, Hwang YC, Oh WM, et al. Thermal analysis of bulk filled composite resin polymerization using various light curing modes according to the curing depth and approximation to the cavity wall. J Appl Oral Sci 2013;21:293-9.

[25] Watts DC, Alnazzawi A. Temperature-dependent polymerization shrinkage stress kinetics of resin-composites. Dent Mater 2014;30:654-60.

[26]Chiang MY, Giuseppetti AA, Qian J, Dunkers JP, Antonucci JM, Schumacher GE, et al. Analyses of a cantilever-beam based instrument for evaluating the development of polymerization stresses. Dent Mater 2011;27:899-905.

[27] Wang Z, Landis FA, Giuseppetti AA, Lin-Gibson S, Chiang MY. Simultaneous measurement of polymerization stress and curing kinetics for photo-polymerized composites with high filler contents. Dent Mater 2014;30:1316-24.

[28] Stansbury JW, Dickens SH. Determination of double bond conversion in dental resins by near infrared spectroscopy. Dent Mater 2001;17:71-9.

[29] Schneider LF, Cavalcante LM, Silikas N. Shrinkage Stresses Generated during ResinComposite Applications: A Review. J Dent Biomech 2010;2010.

[30]Feilzer AJ, De Gee AJ, Davidson CL. Quantitative determination of stress reduction by flow in composite restorations. Dent Mater 1990;6:167-71.

[31]Lu H, Stansbury JW, Dickens SH, Eichmiller FC, Bowman CN. Probing the origins and control of shrinkage stress in dental resin composites. II. Novel method of simultaneous measurement of polymerization shrinkage stress and conversion. J Biomed Mater Res B Appl Biomater 2004;71:206-13.

[32] Jafarpour S, El-Badrawy W, Jazi HS, McComb D. Effect of composite insertion technique on cuspal deflection using an in vitro simulation model. Oper Dent 2012;37:299-305.

[33] Sideridou I, Achilias DS, Kyrikou E. Thermal expansion characteristics of light-cured dental resins and resin composites. Biomaterials. 2004;25:3087-97.

[34]Baroudi K, Silikas N, Watts DC. In vitro pulp chamber temperature rise from irradiation and exotherm of flowable composites. Int J Paediatr Dent 2009;19:48-54.

[35] Mucci V, Arenas G, Duchowicz R, Cook WD, Vallo C. Influence of thermal expansion on shrinkage during photopolymerization of dental resins based on bis-GMA/TEGDMA. Dent Mater 2009;25:103-14. 
[36] Yamasaki LC, De Vito Moraes AG, Barros M, Lewis S, Francci C, Stansbury JW, et al. Polymerization development of "low-shrink" resin composites: Reaction kinetics, polymerization stress and quality of network. Dent Mater 2013;29:e169-79.

[37]Boaro LC, Goncalves F, Braga RR. Influence of the bonding substrate in dental composite polymerization stress testing. Acta Biomater 2010;6:547-51.

[38] Watts DC, Marouf AS, Al-Hindi AM. Photo-polymerization shrinkage-stress kinetics in resin-composites: methods development. Dent Mater 2003;19:1-11.

[39] Kim RJ, Kim YJ, Choi NS, Lee IB. Polymerization shrinkage, modulus, and shrinkage stress related to tooth-restoration interfacial debonding in bulk-fill composites. J Dent2015;43:4309.

[40]Rodrigues FP, Lima RG, Muench A, Watts DC, Ballester RY. A method for calculating the compliance of bonded-interfaces under shrinkage: validation for Class I cavities. Dent Mater 2014;30:936-44. 
Table 1-Investigated materials from 3M ESPE.

\begin{tabular}{|c|c|c|c|c|c|c|c|}
\hline Material & Code & Type & Shade & Resin Composition & $\begin{array}{c}\text { Filler } \\
\text { composition }\end{array}$ & $\begin{array}{c}\text { Filler } \\
\text { Content } \\
\end{array}$ & Filler size \\
\hline $\begin{array}{l}\text { Filtek Bulk } \\
\text { Fill }\end{array}$ & FBF & $\begin{array}{l}\text { Flowable } \\
\text { bulk fill }\end{array}$ & Universal & $\begin{array}{l}\text { Bis-GMA }(1-10 \%), \\
\text { UDMA }(10-20 \%), \text { Bis- } \\
\text { EMA(1-10\%), Procrylat } \\
\text { resins }(10-20 \%)\end{array}$ & $\begin{array}{l}\text { Zirconia/silica, } \\
\text { Ytterbium } \\
\text { trifluoride }\end{array}$ & $64.5 \mathrm{wt} \%$ & $\begin{array}{c}0.01 \text { to } 3.5 \mu \mathrm{m} \\
\text { (Zirconia/silica), } \\
0.1 \text { to } 5.0 \mu \mathrm{m} \\
\text { (Ytterbium } \\
\text { trifluoride) }\end{array}$ \\
\hline Filtek Z250 & $\mathrm{Z} 250$ & $\begin{array}{l}\text { Packable } \\
\text { composite }\end{array}$ & A3 & $\begin{array}{c}\text { Bis-GMA }(1-10 \%) \text {, } \\
\text { UDMA }(1-10 \%), \text { Bis- } \\
\text { EMA }(1-10 \%)\end{array}$ & Zirconia/silica & $82 \mathrm{wt} \%$ & $0.01-3.5 \mu \mathrm{m}$ \\
\hline
\end{tabular}



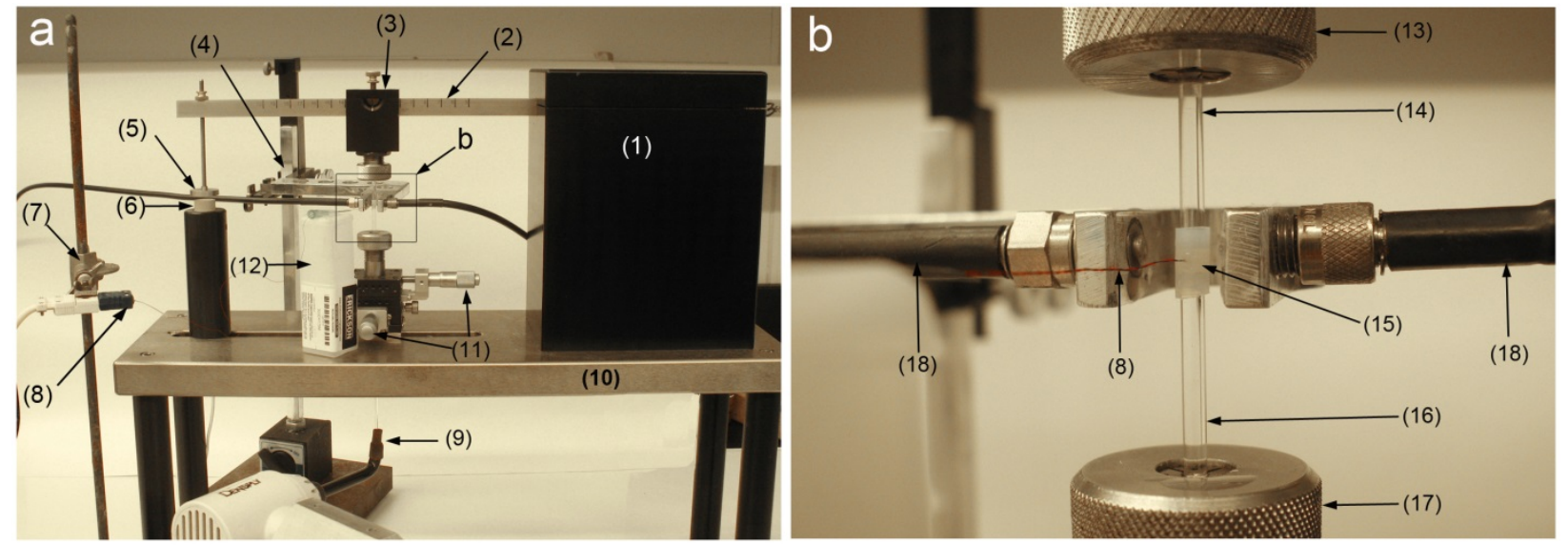

Figure 1. Cantilever-beam based instrument for the simultaneous measurement of polymerization stress, degree of conversion and temperature change.(a) overall view; (b) close view of the sample mounting region. (1) cantilever-beam holder; (2) cantilever beam; (3) upper collet holder; (4) NIR cable holder; (5) flat metal target; (6) probe sensor; (7) thermocouple holder; (8) K-type microprobe thermocouple (0.1 mm diameter, Physitemp Instruments, Clifton, NJ); (9) curing light guide; (10) base stand; (11) X-Y stages; (12) thermocouple holder; (13) upper collet; (14) upper quartz rod; (15) sample encased by PTEE sleeve; (16) lower quartz rod; (17) lower collet; (18) NIR optical fibers. 

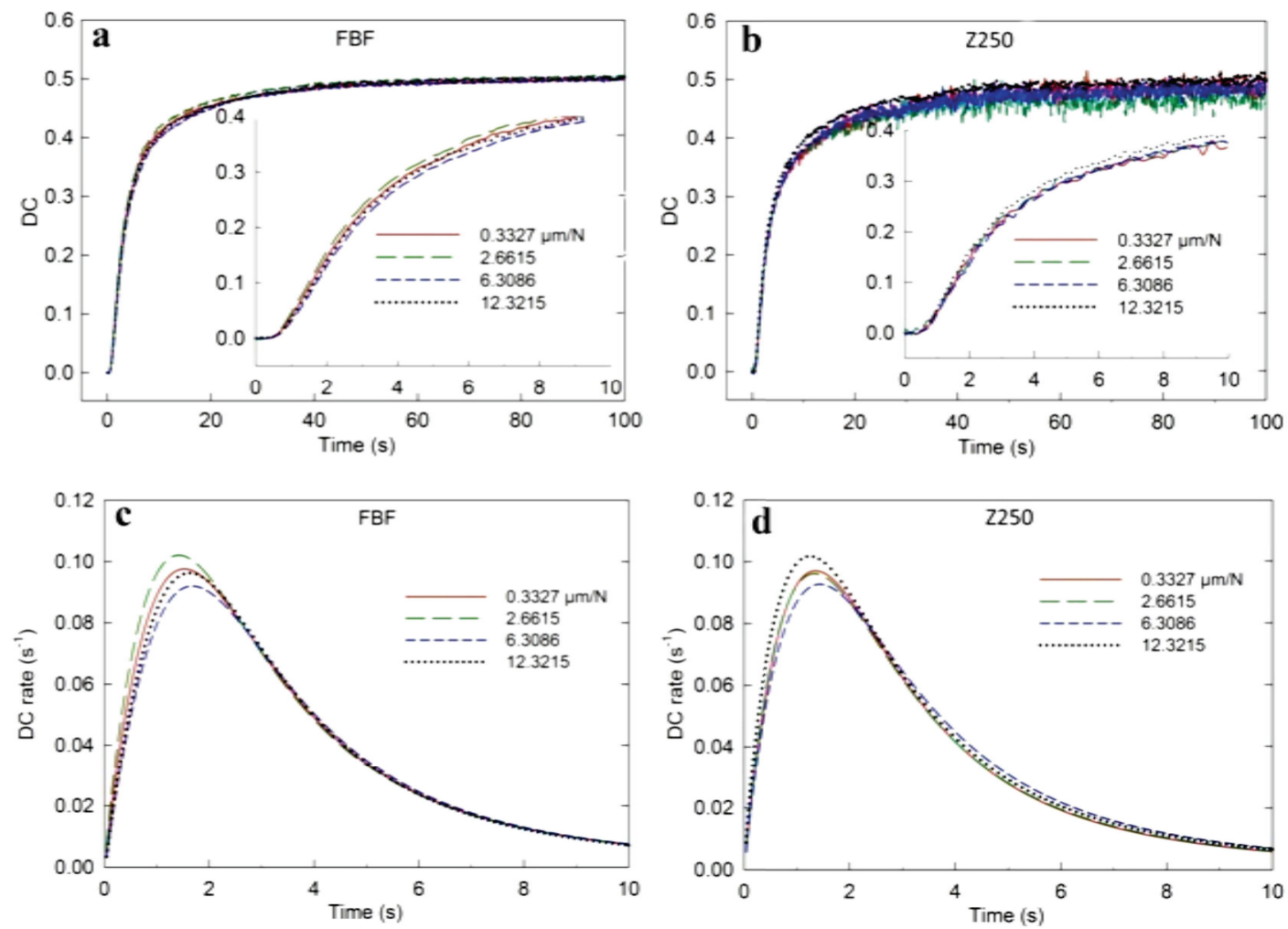

Figure 2.(a \& b) DC development in the beginning $100 \mathrm{~s}$ as well as the initial $10 \mathrm{~s}$ (shown in the insets), and (c \& d) DC rate in the first $10 \mathrm{~s}$ under different compliances. 


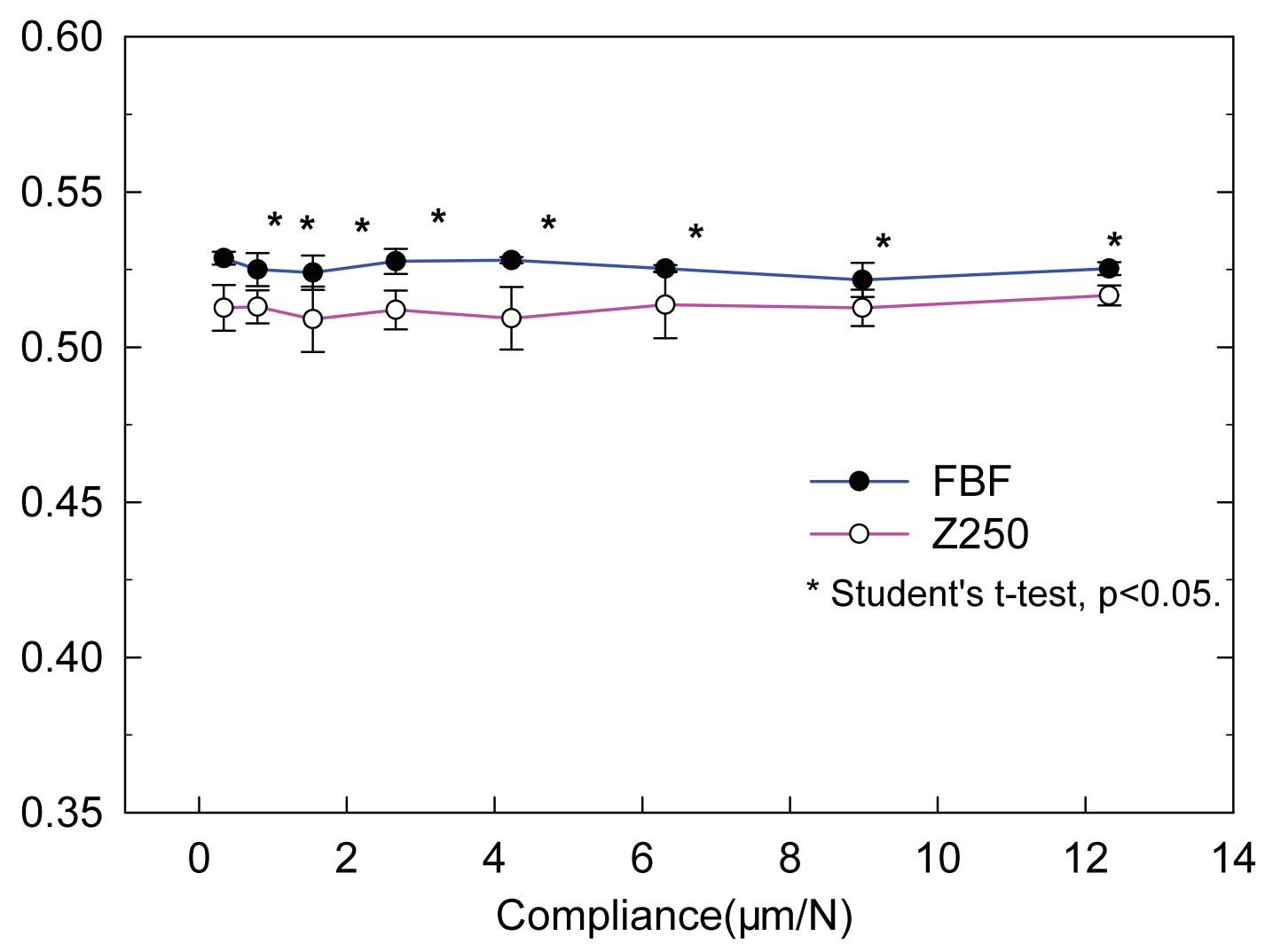

Figure3. Maximum DC of FBF at 10 min after irradiation under different compliances in contrast to Z250. Student's t-test showed statistical difference of DC between the two materials for each compliance. 

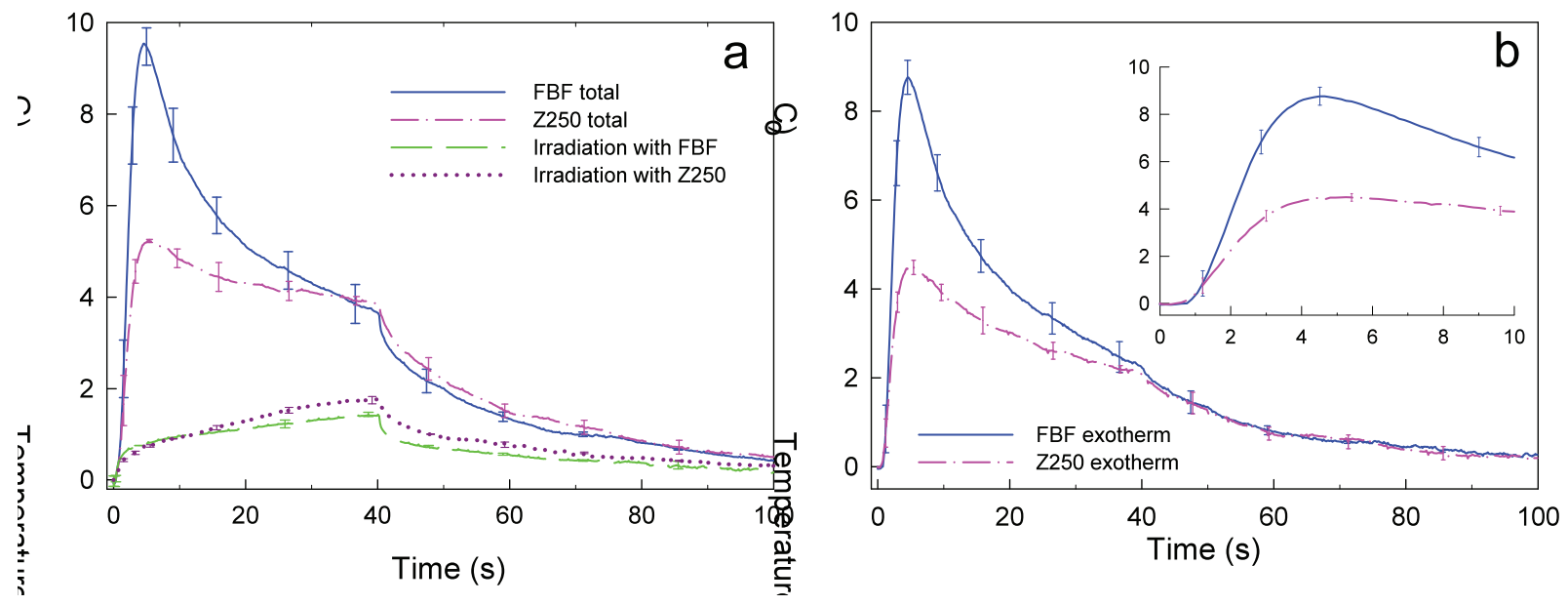

Figure4. Real-time temperature change (exotherm) for the initial 100s of the photopolymerization: (a) the total temperature change and the irradiation temperature change and (b) the net exotherm of the materials. The inset shows the exotherm in the first $10 \mathrm{~s}$. 

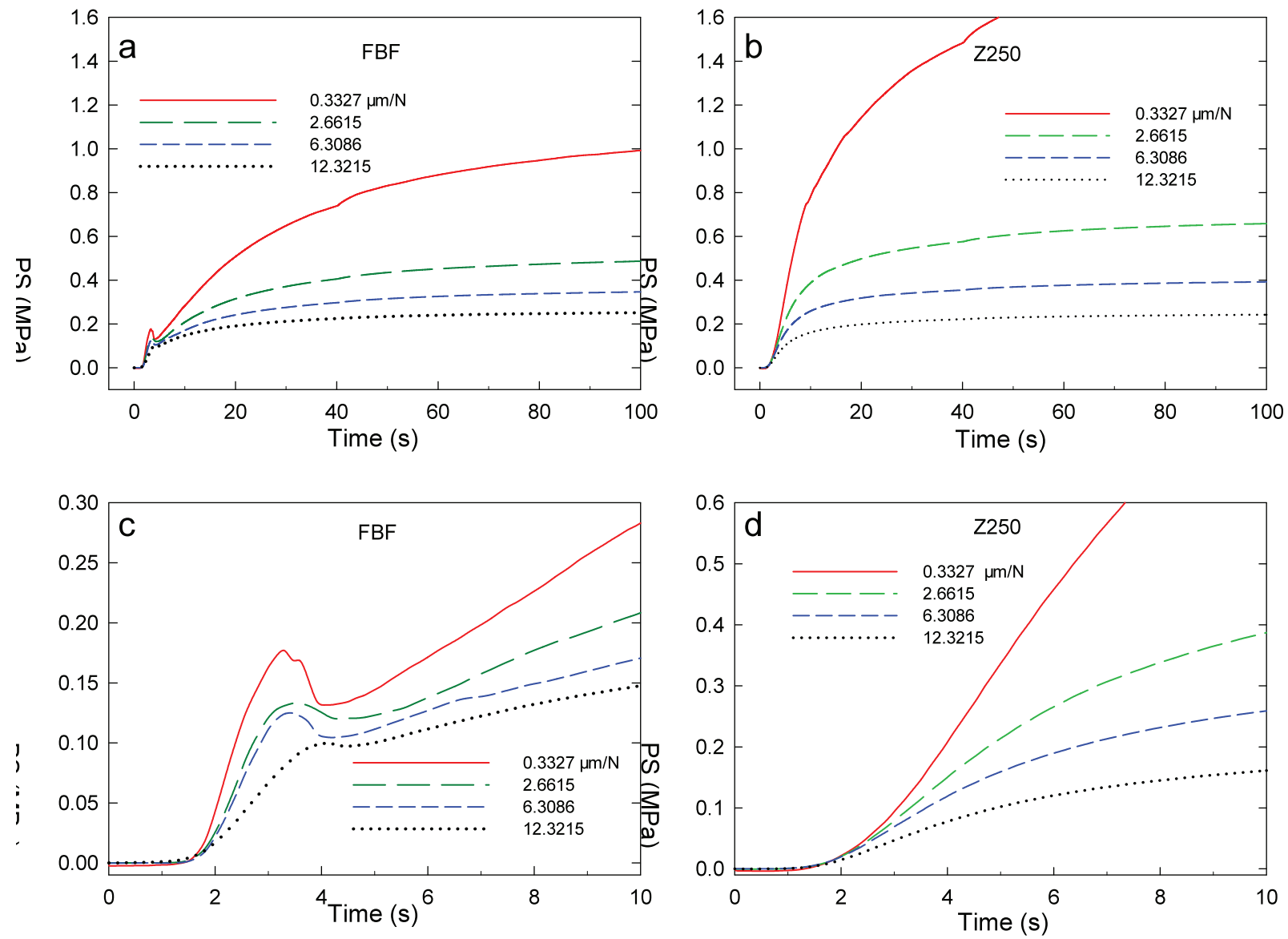

Figure 5. (a \& b) Profiles of the typical PS evolution of FBF and Z250 in the beginning $100 \mathrm{~s}$ and (c \& d) during the initial 10 seconds. 

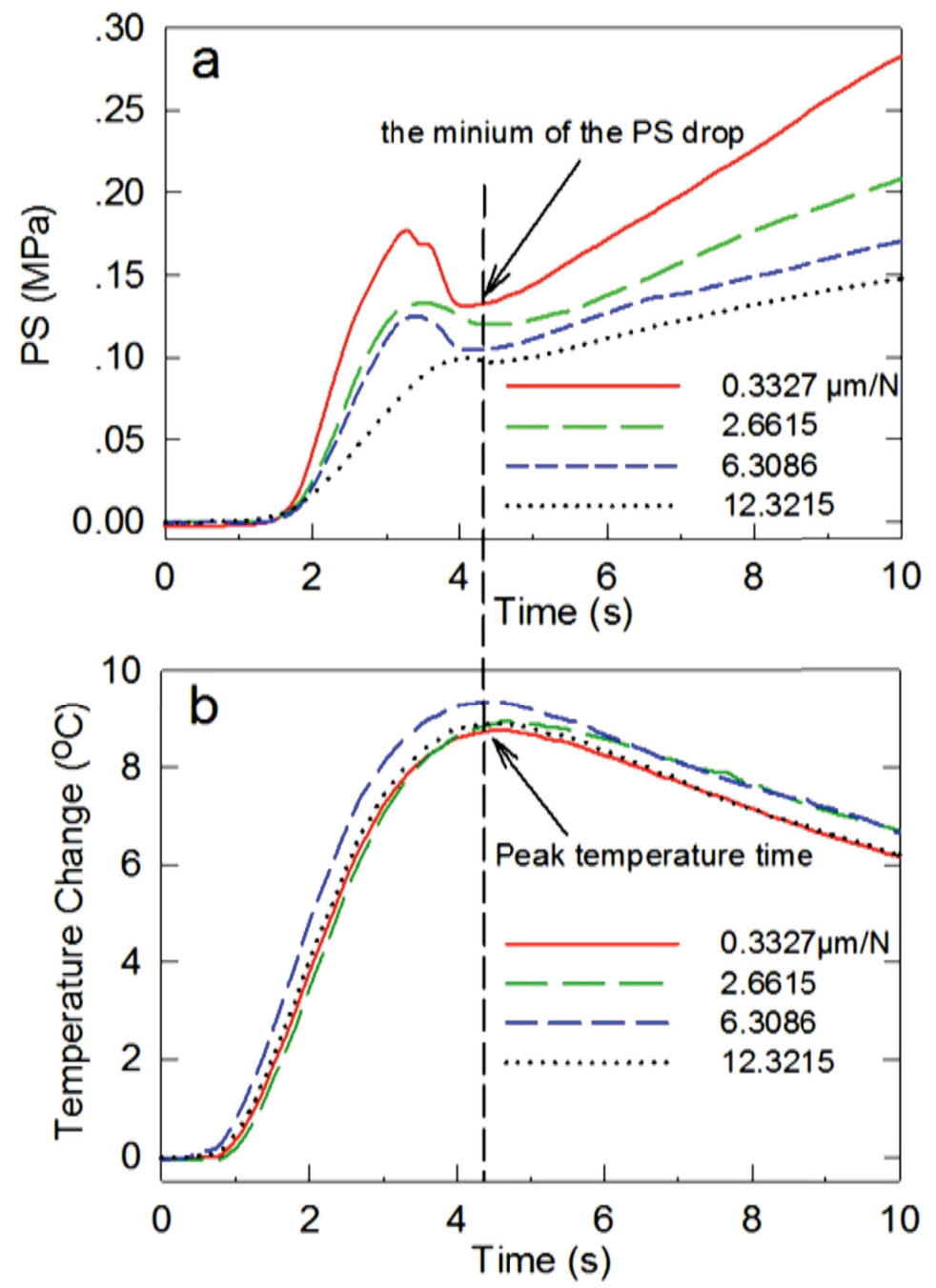

Figure 6. Comparison of the time where (a) the minimum of the PS drop occurs and (b) the maximum temperature of the polymerization exotherm. 


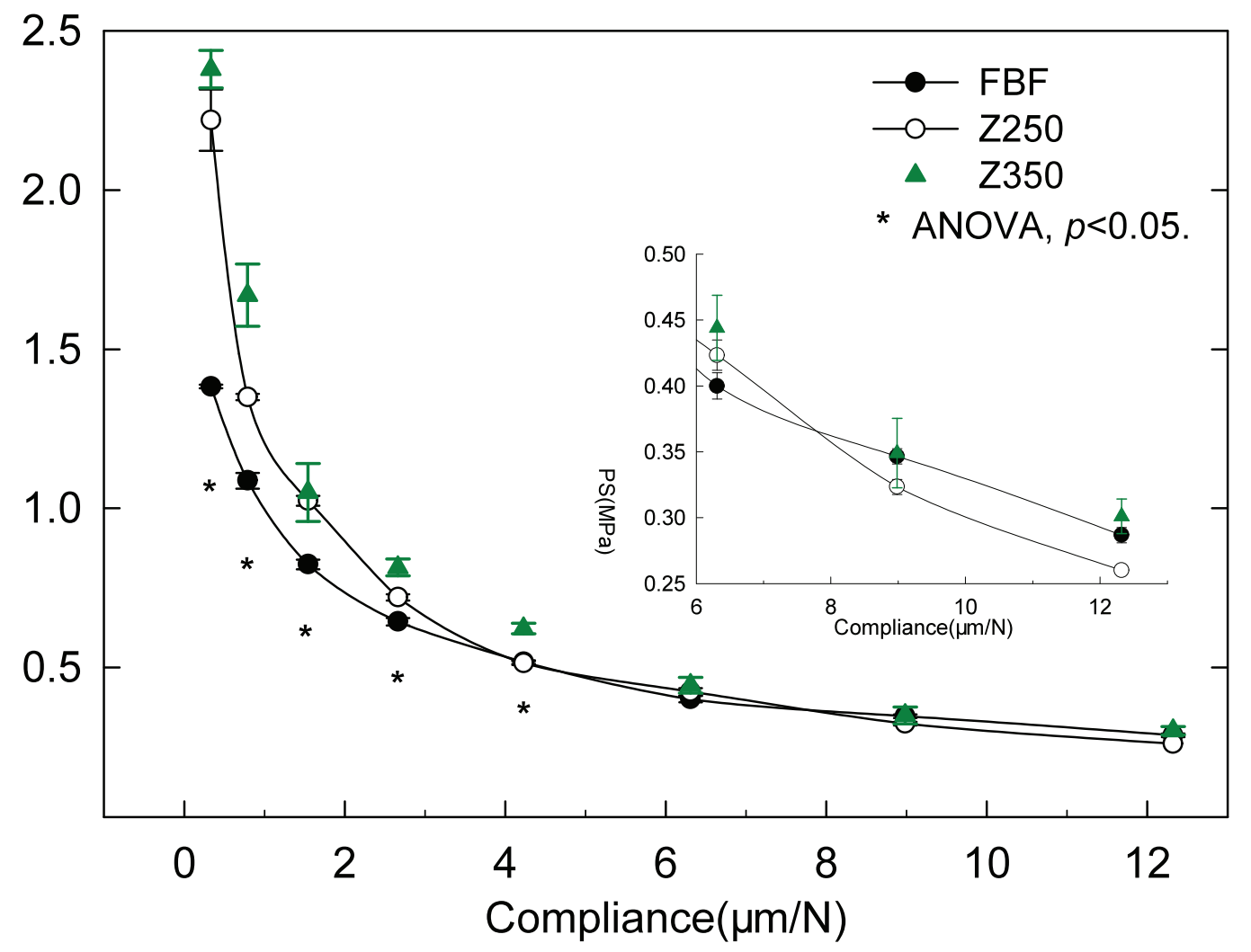

Figure7. The final PS of the FBF at 10 min after irradiation under different compliances in contrast to Z250 and Z350. Analysis of variance (ANOVA) showed significant difference of PS between the other two materials when the compliance was less than approximately $4 \mu \mathrm{m} / \mathrm{N}$, while no statistical difference was observed when the compliance was greater than $4 \mu \mathrm{m} / \mathrm{N}$. 